\title{
Patient safety culture in a large teaching hospital in Riyadh: baseline assessment, comparative analysis and opportunities for improvement
}

\author{
Fadi El-Jardali ${ }^{1,2^{*}}$, Farheen Sheikh ${ }^{3}$, Nereo A Garcia ${ }^{3}$, Diana Jamal ${ }^{1}$ and Ayman Abdo ${ }^{3}$
}

\begin{abstract}
Background: In light of the immense attention given to patient safety, this paper details the findings of a baseline assessment of the patient safety culture in a large hospital in Riyadh and compares results with regional and international studies that utilized the Hospital Survey on Patient Safety Culture. This study also aims to explore the association between patient safety culture predictors and outcomes, considering respondent characteristics and facility size.

Methods: This cross sectional study adopted a customized version of the HSOPSC and targeted hospital staff fitting sampling criteria (physicians, nurses, clinical and non-clinical staff, pharmacy and laboratory staff, dietary and radiology staff, supervisors, and hospital managers).
\end{abstract}

Results: 3000 questionnaires were sent and 2572 were returned (response rate of 85.7\%). Areas of strength were Organizational Learning and Continuous Improvement and Teamwork within units whereas areas requiring improvement were hospital non-punitive response to error, staffing, and Communication Openness. The comparative analysis noted several areas requiring improvement when results on survey composites were compared with results from Lebanon, and the United States. Regression analysis showed associations between higher patient safety aggregate score and greater age (46 years and above), longer work experience, having a Baccalaureate degree, and being a physician or other health professional.

Conclusions: Patient safety practices are crucial toward improving overall performance and quality of services in healthcare organizations. Much can be done in the sampled organizations and in the context of KSA in general to improve areas of weakness and further enhance areas of strength.

\section{Background}

Patient safety has become a major priority to policymakers, healthcare providers and managers. Instigating a strong patient safety culture is pivotal for promoting this concept among healthcare professionals and sustaining this concept in healthcare organizations. Making patient safety culture a top priority is dependant on having a strong and positive patient safety culture [1]. Some components of a strong patient safety culture include open communication, teamwork, and acknowledged mutual

\footnotetext{
* Correspondence: fe08@aub.edu.lb

${ }^{1}$ Department of Health Management and Policy, Faculty of Health Sciences, American University of Beirut, Beirut, Lebanon

2Department of Clinical Epidemiology and Biostatistics, McMaster University, Canada, MML-417, 1280 Main St. West, Hamilton, Ontario L8S 4L6, Canada

Full list of author information is available at the end of the article
}

dependency [2]. Assessing a healthcare organization's patient safety culture is the first step for developing a strong and solid safety culture [3]. Reflecting that, many international accreditation organizations now require patient safety culture assessments to evaluate the perception of healthcare staff on issues such as teamwork, actions taken by management and leadership to support and promote patient safety, staffing issues, frequency of incident reporting, and other patient safety culture issues [4]. Such assessments allow healthcare organizations to obtain a clear view of areas requiring attention to strengthen their patient safety culture [5] and identify specific challenges relating to patient safety within hospital units [4]. Most importantly, healthcare organizations conducting such assessments can benchmark their results against similar surveys conducted within their country or on

\section{Biomed Central}


an international level [6]. A widely used tool for evaluating patient safety culture is the Hospital Survey on Patient Safety Culture (HSOPSC) [7]. The HSOPSC measures 12 patient safety culture composites representing several patient safety culture predictors. The HSOPSC also requires respondents to give their work area/unit a patient safety grade and to answer a question on the number of events reported in the past 12 months [7].

Evidence in the literature identifies several predictors for a strong and positive patient safety culture such as communication, information flow between and across units, common vision on the importance of patient safety, solid and constant commitment from management and leadership, and a non-punitive approach to incident and error reporting [8]. Despite the wealth of evidence published on patient safety culture in recent years, there is limited literature on this topic in the Arab world and the Kingdom of Saudi Arabia (KSA) in particular. A previous study conducted in 2009 in Riyadh identified organizational learning as the most positive aspect and non-punitive response to error as the weakest aspect of patient safety culture in public and private hospitals [9]. In 2010, a similar study utilizing the HSOPSC identified organizational learning and continuous improvement, teamwork within units, and feedback and communication about errors as areas of strength and event reporting, non-punitive response to error, staffing, and teamwork across hospital units as areas requiring improvement [10]. A study conducted in Turkey identified teamwork within units and overall perceptions of safety as areas of strength and frequency of event reporting and non-punitive response to error as areas requiring improvement [11]. The study highlighted infrequent levels event reporting was low and the majority of staff did not report or provide feedback about errors [11].

The realm of patient safety culture was also explored in Lebanon through surveying 6807 hospital employees in 68 hospitals. Using an Arabic version of the HSOPSC, the study identified the most critical issues related to patient safety culture and potential strategies to implement the patient safety accreditation standards. Areas of strength as reported by sampled respondents included teamwork within units, hospital management support for patient safety, and organizational learning and continuous improvement. However, areas of weakness included teamwork across hospital units, hospital handoffs and transitions, staffing, and non-punitive response to error [12]. Approximately $60 \%$ of respondents reported not completing any event reports in the past 12 months and over $70 \%$ gave their units an "Excellent/Very Good" patient safety grade. An aggregate score for all patient safety composites was regressed against respondent characteristics. A higher aggregate score was associated with longer years of experience, being nurses or pharmacists, interaction with patients, and working at an accredited hospital [12]. A follow up study was conducted to identify predictors and outcomes of patient safety culture. Better patient safety grades were associated with higher scores on supervisor/manager expectations, organizational learning and continuous improvement, teamwork within hospital units, feedback and communication about errors, staffing, and hospital management support for patient safety and hospital handoffs and transitions. Event reporting was found to be associated with higher scores on for feedback and communication about errors and lower scores on hospital handoffs and transition. Frequency of event reporting was associated with higher scores on organizational learning and continuous improvement, communication and openness, feedback and communication, non-punitive response to errors, hospital management support for patient safety, and teamwork across hospital units. Better overall perception about patient safety was associated with higher scores on supervisor/manager expectations and actions promoting safety, organizational learning and continuous improvement, teamwork within hospital units, non-punitive response to error, hospital management support for patient safety, and hospital handoffs and transitions [13].

\section{Objectives}

The objective of this study was to conduct a baseline assessment of the patient safety culture in a large hospital in Riyadh, Kingdom of Saudi Arabia (the hospital is composed of two sites, one large with 800 beds and the other small with 104 beds) and compare results with regional and international studies that utilized the same tool. This study aimed at exploring the association between patient safety culture predictors and outcomes, taking into consideration respondent characteristics and facility size.

\section{Methods}

\section{Design, setting and sampling}

This cross sectional study adopted a customized version of the Hospital Survey on Patient Safety Culture (HSOPSC) developed by the Agency for Healthcare Research and Quality. The survey tool was translated to Arabic to account for employees who are not very comfortable with English. It should be noted that the Arabic version of the survey was adapted from a study conducted in Lebanon which utilized this translated version $[12,13]$. The survey was pilot tested with 20 employees who were not included in the final sample. Few modifications were done to the questionnaire as a result and they were mainly limited to adding more departments in the distribution list.

The hospital is a tertiary care university facility that has a total capacity of 904 beds with all major medical specialties and services. It receives referral patients from 
all over the country. The hospital is composed of two sites, Site A which is large (800 beds) and Site B which is small (104 beds).

The survey targeted selected hospital staff including physicians, nurses, clinical and non-clinical staff, pharmacy and laboratory staff, dietary and radiology staff, supervisors, and hospital managers. The two sites had a total of 5200 hospital employees of which 3000 fit the inclusion criteria. Data collection spanned several months and was available in electronic format (December 2011 to March 2012) and hard copies (February 2012 to March 2012). The first page of the survey included a consent form which included information about the study and definitions of terms used. Employees were not asked to sign on the consent form or any other page of the survey; they were asked to return the hard copies of the survey in sealed envlopes to one of 38 available collection boxes placed in designated Points of Contact (POC) assigned to different departments.

\section{Data management and analysis}

Data collected using the hard copies of the survey were entered using MS Excel. Surveys filled electronically were saved onto a web-based application then exported for data analysis on SPSS. Data was analyzed using SPSS 19.0 at a significance level of 0.05 . The HSOPSC is composed of 42 items that measure 12 composites. The HSOPSC included both positively and negatively worded items. Items were scored using a five-point scale reflecting the agreement rate on a five-point frequency scale (both including a neutral category). The percentage of positive responses for each item and composite was calculated; negatively worded items were reversed when computing percent positive response. For example, the responses "Strongly Agree/Agree" or "Most of the time/ Always" are positive responses for positively worded items whereas for reverse worded items, disagreement indicates a positive response, so the responses "Strongly Disagree/Disagree" or "Never/Rarely" are considered. After counting percent positive responses per composite, this number is divided by the total number of responses for this composite to obtain a percent positive. Composite level scores were computed by summation of the items within the composite scales and dividing by the number of items with non-missing values. Cronbach's alpha was used to measure the internal consistency of the 12 composites.

Two of the composites (frequency of events reported and overall perception of safety) are two of the four patient safety culture outcome variables [7]. The remaining two outcome variables are the patient safety grade and the number of events reported [7]. Pearson correlation was used to examine the association between frequency of frequency of events reported and overall perception of safety and the remaining 10 composites at the bi-variate level. Additionally, ANOVA f-test with multiple correction using Bonferroni was used to examine the association between patient safety grade and number of events reported across the two sites (Sites A and B). Cross-tables were constructed and chi-square test was used to examine the association between patient safety grade and number of events reported across the two sites (Sites A and B).

Calculating the item-level and the composite-level percent of positive and negative responses allowed for the identification of areas of strength (at least $75 \%$ of respondents answer positively) and areas with potential for improvement (less than 50\% answer positively). As such, higher values reflect better scores. Univariate analysis was also conducted to summarize demographic characteristics of hospitals and respondents. Bi-variate analysis was conducted to derive potential variables to be included in the regression analyses. All tests were conducted at a significance level of 0.05 .

The four outcome variables were regressed against the 10 composite scores, respondent's position in the hospital, and hospital size. Four regression models were constructed, two adopted Generalized Estimating Equations (the two categorical outcome variables: number of events reported and patient safety grade) and the other two models followed a linear regression model (the two composites for frequency of events reported and overall perception of safety). In the latter models, the independent variables were entered as dummy variables. The two categorical outcomes were recoded into fewer categories for the purpose of this analysis. The outcome on patient safety grade was recoded into three categories "Poor or Failing," "Acceptable," and "Excellent/Good." The outcome on number of events reported was recoded into " $>5$ events reported," " 1 to 5 events reported," and "No events reported".

Prior to data analysis, a data check was conducted to determine whether any of the respondents answered similarly to all questions (filled in the same value for all items). The survey was 3 pages long and as such, a total of 59 surveys for which respondents indicated the same value for $80 \%$ of the questions on the same page were dropped from the analysis. It was initially assumed that respondents would indicate the same value for the entire survey. When this assumption was assessed, only 18 cases were found.

Results on the survey composite were compared against those in three other countries, specifically, Lebanon, and the United States. A weighting exercise was conducted on SPSS to determine whether the difference in results from each country were significantly different. The percent positive responses for each of the composites were grouped in an MS Excel sheet and countries were compared collectively and in pairs. Given differences in types of health facilities, size of facilities, 
number of respondents, and other additional factors, this analysis was done for comparative purposes.

\section{Results}

\section{General results}

A total of 2,572 of the 3,000 questionnaires sent to the two sites were returned complete (2033 from Site A and 539 from Site B) yielding an overall response rate of $85.7 \%$. Responses to the electronic format of the survey were 1524 (59.3\%) whereas 1047 employees returned the hard copy of the survey (40.7\%). The majority of sampled respondents were females (71.4\%) with approximately half within the 30 to 45 age group (45.3\%). A total of $43.6 \%$ held a Diploma while $38.9 \%$ had a Baccalaureate Degree (Table 1). Around a third of respondents indicated working in the Administration (27.1\%) while $20.1 \%$ worked in Medical units, $19.6 \%$ in Surgical units and 21.2\% in other units. Half the sampled respondents indicated being Registered Nurses (50.1\%), 12.0\% were Technicians, $6.1 \%$ were Attending/Staff Physicians, and 5.2\% were Unit assistants, clerks or secretaries (Table 1). A third of respondents had 1 to 5 years of experience (30.5\%) while $25 \%$ had 6 to 10 years of experience and $18.6 \%$ had less than 1 year of experience. The majority of respondents indicated that their work required direct contact with patients (76.1\%). Approximately half the sampled respondents gave their hospital a Very Good patient safety grade (49\%). Slightly over half the sampled respondents reported no events (52.7\%), approximately a third (28.7\%) reported 1 to 2 events, and 13\% reported 3 to 5 events. It is worth noting that only $1.4 \%$ of respondents reported 21 or more events (Table 1).

Determining Areas of strengths and areas requiring improvement according to patient safety culture composites results

The twelve dimensions were examined to determine areas of strength (those where percent positive rating exceeds 75\%) and those requiring improvement (scoring below 50\%). The dimensions with the highest positive score and are thus considered areas of strength were Organizational Learning and Continuous Improvement (79.6\%), and Teamwork within units (78.5\%). Dimensions scoring the lowest and as such can be considered areas requiring improvement were hospital non-punitive response to error (26.8\%), staffing (35.1\%), and Communication Openness (42.9\%) (Figure 1).

Items considered areas of strength and other requiting improvement were then examined. One major area of strength was highlighted by the responses to the item on whether the hospital is actively doing things to improve patient safety to which percent positive response was $90 \%$. Other areas of strength were revealed within the dimension on Teamwork within units whereby the item
Table 1 Socio-demographic and professional characteristics of respondents in addition to frequency of events and patient safety grade

\begin{tabular}{|c|c|c|}
\hline Characteristics & $\mathrm{N}$ & $\%$ \\
\hline \multicolumn{3}{|l|}{ Gender } \\
\hline Male & 728 & $28.6 \%$ \\
\hline Female & 1820 & $71.4 \%$ \\
\hline \multicolumn{3}{|l|}{ Age (years) } \\
\hline$<30$ & 854 & $33.7 \%$ \\
\hline $30-45$ & 1148 & $45.3 \%$ \\
\hline $46-55$ & 401 & $15.8 \%$ \\
\hline$\geq 55$ years & 133 & $5.2 \%$ \\
\hline \multicolumn{3}{|l|}{ Degree classification } \\
\hline Under high school & 14 & $0.6 \%$ \\
\hline High school level & 62 & $2.5 \%$ \\
\hline Diploma level & 1082 & $43.6 \%$ \\
\hline Baccalaureate degree & 966 & $38.9 \%$ \\
\hline Masters degree & 124 & $5.0 \%$ \\
\hline Doctorate degree & 112 & $4.5 \%$ \\
\hline Other & 122 & $4.9 \%$ \\
\hline
\end{tabular}

Work area/unit where respondents spend most of their work time

$\begin{array}{lll}\text { Administration } & 697 \quad 27.1 \%\end{array}$

Medical

Surgical

Diagnostics

Other

$536 \quad 20.8 \%$

$503 \quad 19.6 \%$

$277 \quad 10.8 \%$

$545 \quad 21.2 \%$

Respondents' positions at the hospital

Administration/Management $\quad 92 \quad 3.6 \%$

$\begin{array}{lll}\text { Attending/Staff physician } & 158 \quad 6.1 \%\end{array}$

Dietician

Infection control practitioner/Coordinator/Nurse

Patient care assistant/Hospital aide/Care partner

Pharmacist

$46 \quad 1.8 \%$

Physical, occupational, speech therapist

Physician assistant/Nurse practitioner

Registered nurse

$13 \quad 0.5 \%$

Resident physician/Physician in training

Respiratory therapist

Quality staff

Unit assistant/Clerk/Secretary

Technician (e.g., EKG, Lab, Radiology)

Other, please specify:

Experience in current hospital (years)

Less than 1 year

1 to 5 years 
Table 1 Socio-demographic and professional characteristics of respondents in addition to frequency of events and patient safety grade (Continued)

\begin{tabular}{|c|c|c|}
\hline 6 to 10 years & 622 & $25.0 \%$ \\
\hline 11 to 15 years & 290 & $11.7 \%$ \\
\hline 16 to 20 years & 136 & $5.5 \%$ \\
\hline 21 years or more & 217 & $8.7 \%$ \\
\hline \multicolumn{3}{|c|}{ Experience in current work area (years) } \\
\hline Less than 1 year & 436 & $17.3 \%$ \\
\hline 1 to 5 years & 986 & $39.1 \%$ \\
\hline 6 to 10 years & 528 & $20.9 \%$ \\
\hline 11 to 15 years & 245 & $9.7 \%$ \\
\hline 16 to 20 years & 159 & $6.3 \%$ \\
\hline 21 years or more & 168 & $6.7 \%$ \\
\hline \multicolumn{3}{|c|}{ Job involves direct contact with patients } \\
\hline Yes & 1956 & $76.1 \%$ \\
\hline No & 615 & $23.9 \%$ \\
\hline \multicolumn{3}{|l|}{ Patient safety grade } \\
\hline Excellent & 507 & $20.6 \%$ \\
\hline Very good & 1207 & $49.0 \%$ \\
\hline Acceptable & 632 & $25.6 \%$ \\
\hline Poor & 100 & $4.1 \%$ \\
\hline Failing & 19 & $0.8 \%$ \\
\hline \multicolumn{3}{|l|}{ Number of events reported } \\
\hline No events & 1275 & $52.7 \%$ \\
\hline 1 to 2 event reports & 677 & $28.0 \%$ \\
\hline 3 to 5 event reports & 315 & $13.0 \%$ \\
\hline 6 to 10 event reports & 84 & $3.5 \%$ \\
\hline 11 to 20 event reports & 36 & $1.5 \%$ \\
\hline 21 event reports or more & 34 & $1.4 \%$ \\
\hline
\end{tabular}

on whether staff support one another within a unit received $84.7 \%$ positive responses, whereas the item on the degree to which staff we work together as a team to get the work done when there is a lot of work to be done received $81.6 \%$ percent positive scores. Moreover, $80.7 \%$ of respondents responded positively when it came to whether staff members treat each other with respect within the unit (Table 2). Some of the areas requiring improvement pertained to the dimension on staffing whereby respondents reported that staff work longer hours than best for patient safety (19.3\% positive) and $24.8 \%$ indicated that they try to do too much too quickly when work is in "crisis mode." Other areas requiring improvement pertained to non-punitive response to error whereby $31.4 \%$ of staff felt like their mistakes were held against them, and $32.5 \%$ indicated feeling as though they were being written up when an event is reported (Table 2).
Additional areas of strength and those requiring improvement are detailed in Table 2.

\section{Comparative against regional and international findings}

Patient safety culture composite scores were compared to similar studies done in Lebanon, and the United States. The sampled hospital in Riyadh appeared to fare better on the dimension pertaining to Teamwork across hospital units, Hospital Handoffs and Transitions and Organizational learning and continuous improvement than hospitals in Lebanon [12], and the US [14]. Compared to Lebanon, the sampled hospital scores much lower on Hospital management support for patient safety, Feedback and communication about error, Supervisor Manager Expectations and Actions Promoting Patient Safety, Frequency of Events Reported, Overall Perception of Patient Safety, and Communication and Openness (Figure 1). When comparing findings against those of the study conducted in the US [14], the sampled hospital was found to need improvement on several composites including Non-punitive response to error, Staffing, Communication openness, Overall perception of patient safety, and Supervisor Manager Expectations and Actions Promoting Patient Safety (See Figure 1).

\section{Correlations between patient safety culture composites}

Despite one exception, the 12 composites were found to be significantly but moderately correlated with varying degrees in the strength of these correlations. Within the composite on frequency of events reported, the strongest correlation was observed for feedback and communication about error (Pearson $r=0.413$ ) while the weakest correlation was for that on supervisor manager expectations to promote patient safety (Pearson $r=0.081$ ). It was interesting to observe a negative (albeit relatively weak) correlation between staffing and frequency of events reported (Pearson $r=-0.087$ ) (See Table 3).

As for the composite on overall perception of patient safety, the strongest correlation was that for hospital management support for patient safety (Pearson $r=0.352$ ) while the weakest was that for non-punitive response to error (Pearson $r=0.176$ ). It was also interesting to observe a weak correlation between communication and openness and overall perception of patient safety (See Table 3).

\section{Comparison of means between outcome variables and patient safety composites}

Significantly different mean scores were observed for patient safety grade and all 10 patient safety culture composites with highest mean scores observed for respondents who indicated an Excellent/Very Good grade (See Table 4). The outcome of number of events reported was significantly associated with feedback and communication about error, hospital management support for 


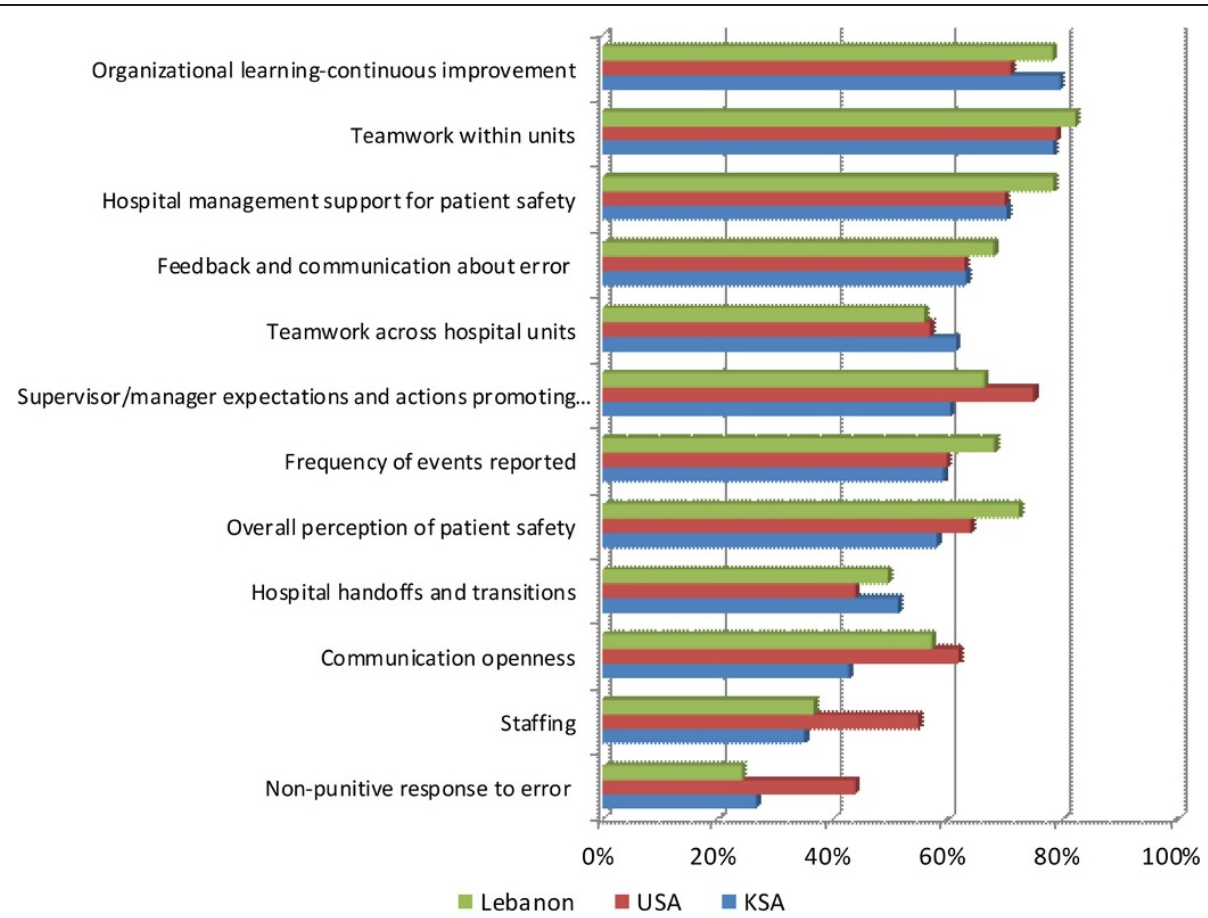

Figure 1 Composite-level average $\%$ positive response for KSA compared to that of Lebanon and USA.

patient safety, hospital handoffs and transitions, and teamwork across hospital units with the highest mean scores observed for respondents reporting 1 to 5 events (See Table 4).

\section{Comparison of responses across the two facilities}

Patient safety composites were significantly different across the two facilities of different size. Specifically, higher scores were observed in the small facility for the composites measuring overall perception of safety, supervisor manager expectations and actions to promote safety, teamwork within hospital units, communication and openness, nonpunitive response to error, hospital management support for patient safety, and teamwork across hospital units (See Table 5).

\section{Generalized estimating equations for the patient safety composite scores and respondent and hospital characteristics against the patient safety grade and the number of events reported Patient safety grade}

As detailed in Table 6, a one unit increase on most patient safety culture composites increased odds of reporting better patient safety grades. In fact, patient safety grades increased by $2.80(95 \% \mathrm{CI}=2.55-3.08)$ for every unit increase in Hospital Management Support for Patient Safety, $1.91(95 \% \mathrm{CI}=1.63-2.25)$ for every unit increase in Organizational learning and Continuous Improvement and by $1.44(95 \% \mathrm{CI}=1.33-1.56)$ for every unit increase in Feedback and Communications About Error. The only composite that was not found to be significantly associated with patient safety grade was that measuring Hospital Handoffs \& Transitions.

Female respondents had 0.50 lower odds $(95 \% \mathrm{CI}=$ 0.39 - 0.65) of reporting better patient safety grades. Respondents aged between 30 and 45 and those above 55 also had lower odds of reporting better patient safety grades $(\mathrm{OR}=0.91,95 \% \mathrm{CI}=0.89-0.93$ and $\mathrm{OR}=0.66$, $95 \% \mathrm{CI}=0.49-0.89$ respectively). Experience was associated with higher patient safety grades whereby respondents who had 6 to 20 years of experience had greater odds of reporting higher patient safety grades (See Table 6). Degrees were negatively associated with patient safety grades whereby increasing educational attainment was associated with lower patient safety grades (See Table 6). As for respondent positions, attending physicians, dieticians, registered nurses, resident physicians, respiratory therapist, quality staff and unit assistants and clerks had lower odds of reporting higher patient safety grades. Respondents working in the small site of the hospital had significantly higher odds of reporting better patient safety grades $(\mathrm{OR}=1.58,95 \% \mathrm{CI}=1.25-1.99)$ (See Table 6).

\section{Number of events reported}

A one unit increase in some composites was found to increase number of events whereby an increase in some others had the opposite effect. An increase in Feedback and Communication about Error, and non-punitive response to 
Table 2 Cronbach's Alpha and distribution of positive responses and scores for survey composites and items

Composites and survey items
Overall perception of safety (Cronbach's $\mathbf{a}=\mathbf{0 . 2 1 4}$ )
It is just by chance that more serious mistakes do not happen around here $(\mathrm{R})^{* *}$
Patient safety is never sacrificed to get more work done
We have patient safety problems in this unit ( $R$ )
Our policies and procedures and systems are effective in preventing errors

Average \% positive
response*

My supervisor/manager says a good word when he/she sees a job done according to established patient safety procedures

My supervisor/manager seriously considers staff suggestions for improving patient safety

Whenever pressure builds up, my supervisor/manager wants us to work faster, even if it means taking shortcuts (R)

My supervisor/manager overlooks patient safety problems that happen over and over (R)

\section{6}

Organizational learning and continuous improvement (Cronbach's $a=0.704)$

We are actively doing things to improve patient safety

Mistake have led to positive changes here

After we make changes to improve patient safety, we evaluate their effectiveness

Teamwork within units (Cronbach's $a=0.814$ )

Staff support one another in this unit

When a lot of work needs to be done quickly, we work together as a team to get the work done

In this unit, people treat each other with respect

When members of this unit get really busy, other members of the same unit help out

Non-punitive response to error (Cronbach's $\alpha=0.643$ )

Staff feel like their mistakes are held against them (R)

When an event is reported, it feels like the person is being written up, not the problem ( $R$ )

Staff worry that mistakes they make are kept in their personnel file (R)

Staffing (Cronbach's $a=0.238$ )

We have enough staff to handle the workload

Staff in this unit work longer hours than is best for patient care (R)

We use agency/temporary staff than is best for patient care (R)

When the work is in "crisis mode" we try to do too much, too quickly (R)

Hospital management support for patient safety (Cronbach's $\alpha=0.577$ )

Hospital management provides a work climate that promotes patient safety

The actions of hospital management show that patient safety is a top priority

Hospital management seems interested in patient safety only after an adverse event happens (R)

Teamwork across hospital units (Cronbach's $\mathbf{a}=\mathbf{0 . 6 4 3 \text { ) }}$

There is good cooperation among hospital units that need to work together

Hospital units work well together to provide the best care for patients

Hospital units do not coordinate well with each other and this might affect patient care (R)

It is often not easy to work with staff from other hospital units (R)

Hospital handoffs \& transitions (Cronbach's $a=0.770$ )

Things "fall between the cracks", i.e., things might go uncontrolled and get lost (ex: medical records, medical treatment, patient information and education, discharge criteria) when transferring patients from one unit to another $(\mathrm{R})$

Important patient care information is often lost during shift changes (R)

Problems often occur in the exchange of information across hospital units (R)

Shift changes are problematic for patients in this hospital (R)
71.8

74.8

51.0

$3.46(0.65)$

$3.69(1.05)$

$3.77(0.97)$

$3.27(1.09)$

$3.13(1.18)$

$3.89(0.69)$

$4.19(0.82)$

$3.63(0.93)$

$3.84(0.87)$

3.85 (0.75)

$3.97(0.88)$

$3.93(0.89)$

$3.92(0.91)$

3.57 (1.08)

$2.68(0.81)$

$2.83(1.09)$

$2.85(1.09)$

2.37 (1.02)

2.84 (0.62)

$3.05(1.20)$

$2.41(1.09)$

3.34 (1.11)

2.58 (1.09)

3.69 (0.76)

$3.76(0.96)$

$3.97(0.96)$

$3.32(1.15)$

3.36 (0.79)

$3.58(0.96)$

$3.90(0.96)$

$3.29(1.12)$

$3.30(1.03)$

$3.52(0.71)$

$3.20(1.04)$

$3.59(1.02)$

62.3

$3.15(0.99)$

41.6

3.51 (1.05) 
Table 2 Cronbach's Alpha and distribution of positive responses and scores for survey composites and items (Continued)

\begin{tabular}{|c|c|c|}
\hline Communication openness (Cronbach's $a=0.536$ ) & 42.9 & $3.25(0.85)$ \\
\hline Staff will freely speak up if they see something that may negatively affect patient care & 54.2 & $3.53(1.16)$ \\
\hline Staff feel free to question the decisions or actions of those with more authority & 33.3 & $2.94(1.23)$ \\
\hline Staff are afraid to ask questions when something does not feel right (R) & 41.1 & $3.30(1.16)$ \\
\hline Feedback and communications about error (Cronbach's $a=0.793$ ) & 63.3 & $3.73(0.95)$ \\
\hline We are given feedback about changes put into place based on event reports & 48.9 & $3.39(1.13)$ \\
\hline We are informed about errors that happen in this unit & 68.9 & $3.85(1.147)$ \\
\hline In this unit, we discuss ways to prevent errors from happening again & 72.0 & $3.94(1.1)$ \\
\hline Frequency of events reported (Cronbach's $a=0.892)$ & 59.4 & $3.63(1.16)$ \\
\hline When a mistake is made, but is caught and corrected affecting the patient, how often is this reported? & 58.2 & $3.59(1.29)$ \\
\hline When a mistake is made, but has no potential to harm the patient, how often is this reported? & 56.3 & $3.56(1.27)$ \\
\hline When a mistake is made that could harm the patient, but does not, how often is this reported? & 63.7 & $3.74(1.29)$ \\
\hline
\end{tabular}

*the composite-level percentage of positive responses was calculated using the following formula: (number of positive responses to the items in the composite/ total number of responses to the items (positive, neutral, and negative) in the composite (excluding missing responses))* 100 .

**Negatively worded items that were reverse coded.

error led to higher odds of reporting higher number of events. Composites that were associated with lower odds of reporting higher number of events were: Organizational Learning and Continuous Improvement, Teamwork within Units, Staffing, and Hospital Management Support for Patient Safety (See Table 6).

Female respondents had 0.75 lower odds $(95 \% \mathrm{CI}=$ $0.62-0.91)$ of reporting higher number of events. While respondent age was not significantly associated with number of events, a work experience ranging between 6 to 15 years was associated with lower odds of reporting higher number of events. Increasing levels of education was also associated with much greater odds of reporting higher number of events. With regard to positions, all of Attending/Staff Physician; Physical, occupational speech therapists; physician assistant/nurse practitioners; unit assistant/clerks; technicians; and others had lower odds of reporting higher number of events. However, pharmacists and respiratory therapists had greater odds of reporting higher number of events. Working in the smaller hospital site was also associated with reporting lower number of events $(\mathrm{OR}=0.62,95 \% \mathrm{CI}=0.60-0.65)$ (See Table 6).

Linear regression for the patient safety composite scores and respondent and hospital characteristics against the frequency of events reported and the overall perception of safety

\section{Frequency of events reported}

Linear regression analysis showed that a one unit increase in the score on organizational learning and continuous improvement increased the frequency of events reported by 0.24 (P-Value $=0.002$ ) whereas an increase in Feedback and Communications About Error increased frequency of events reported by 0.43 ( $\mathrm{p}$-value $<0.001$ ). However, a one unit increase in Staffing and Teamwork across units

Table 3 Correlations between patient safety culture composites

\begin{tabular}{|c|c|c|c|c|}
\hline & \multicolumn{2}{|c|}{ Frequency of events reported } & \multicolumn{2}{|c|}{ Overall perception of safety } \\
\hline & Pearson $\mathrm{r}$ & $\mathbf{N}$ & Pearson $\mathrm{r}$ & $\mathbf{N}$ \\
\hline Supervisor/Manager expectations and actions promoting safety & $0.081^{*}$ & 1328 & $0.323^{*}$ & 1304 \\
\hline Organizational learning-continuous improvement & $0.311^{*}$ & 1341 & $0.287^{*}$ & 1318 \\
\hline Teamwork within hospital units & $0.186^{*}$ & 1349 & $0.297^{*}$ & 1326 \\
\hline Communication openness & $0.168^{*}$ & 1342 & $0.184^{*}$ & 1311 \\
\hline Feedback and communication about errors & $0.413^{*}$ & 1345 & $0.203^{*}$ & 1315 \\
\hline Non-punitive response to error & 0.023 & 1323 & $0.176^{*}$ & 1304 \\
\hline Staffing & $-0.087^{*}$ & 1328 & $0.222^{*}$ & 1310 \\
\hline Hospital management support for patient safety & $0.265^{*}$ & 1344 & $0.352^{*}$ & 1317 \\
\hline Hospital handoffs and transitions & $0.175^{*}$ & 1311 & $0.222^{*}$ & 1284 \\
\hline Teamwork across hospital units & $0.209^{*}$ & 1321 & $0.276^{*}$ & 1292 \\
\hline
\end{tabular}

${ }^{*}$ Correlation is significant at the 0.01 level (2-tailed). 
Table 4 Comparison of means between patient safety grade and number of events reported with patient safety culture composite scores

\begin{tabular}{|c|c|c|c|c|c|c|c|c|}
\hline & \multicolumn{4}{|c|}{ Patient safety grade } & \multicolumn{4}{|c|}{ Number of events reported } \\
\hline & \multicolumn{2}{|c|}{$\begin{array}{l}\text { Poor or } \\
\text { failing }\end{array}$} & \multirow{2}{*}{$\begin{array}{l}\text { Acceptable } \\
\text { Mean (SD) }\end{array}$} & \multirow{2}{*}{$\begin{array}{l}\text { Excellent/ } \\
\text { Very good } \\
\text { Mean (SD) }\end{array}$} & \multicolumn{2}{|c|}{$\begin{array}{l}\text { No event } \\
\text { reports }\end{array}$} & \multirow{2}{*}{$\begin{array}{l}1 \text { to } 5 \text { event } \\
\text { reports } \\
\text { Mean (SD) }\end{array}$} & \multirow{2}{*}{$\begin{array}{l}>5 \text { events } \\
\text { reported } \\
\text { Mean (SD) }\end{array}$} \\
\hline & Sig. & Mean (SD) & & & Sig. & Mean (SD) & & \\
\hline $\begin{array}{l}\text { Supervisor/Manager expectations } \\
\text { and actions promoting safety }\end{array}$ & $a, b, c$ & $2.94(0.78)$ & $3.29(0.67)$ & $3.60(0.59)$ & & $3.51(0.64)$ & $3.49(0.64)$ & $3.53(0.66)$ \\
\hline $\begin{array}{l}\text { Organizational learning-continuous } \\
\text { improvement }\end{array}$ & $a, b, c$ & $2.95(1.03)$ & $3.80(0.59)$ & $4.10(0.45)$ & & $3.96(0.58)$ & $4.04(0.54)$ & $3.96(0.69)$ \\
\hline Teamwork within hospital units & $a, b, c$ & $3.12(1.05)$ & $3.67(0.67)$ & $4.07(0.53)$ & & $3.94(0.61)$ & $3.96(0.61)$ & $3.91(0.93)$ \\
\hline Communication openness & $a, b, c$ & $2.53(1.08)$ & $2.91(0.81)$ & $3.43(0.80)$ & & $3.27(0.84)$ & $3.26(0.86)$ & $3.39(0.88)$ \\
\hline Feedback and communication about errors & $a, b, c$ & $2.68(1.13)$ & $3.55(0.84)$ & $4.08(0.73)$ & a & $3.81(0.90)$ & $4.01(0.75)$ & $3.94(0.88)$ \\
\hline Non-punitive response to error & c & $2.56(0.96)$ & $2.43(0.74)$ & $2.75(0.78)$ & & $2.65(0.76)$ & $2.65(0.81)$ & $2.81(0.90)$ \\
\hline Staffing & c & $2.74(0.58)$ & $2.75(0.55)$ & $2.90(0.63)$ & & $2.90(0.61)$ & $2.83(0.62)$ & $2.75(0.63)$ \\
\hline $\begin{array}{l}\text { Hospital management support for } \\
\text { patient safety }\end{array}$ & $a, b, c$ & $2.52(0.70)$ & $3.46(0.68)$ & $3.97(0.60)$ & c & $3.79(0.73)$ & $3.84(0.67)$ & $3.64(0.74)$ \\
\hline Hospital handoffs and transitions & $a, b, c$ & $3.03(0.83)$ & $3.19(0.74)$ & $3.56(0.73)$ & c & $3.41(0.78)$ & $3.52(0.74)$ & $3.31(0.71)$ \\
\hline Teamwork across hospital units & $a, b, c$ & $2.68(0.68)$ & $3.30(0.64)$ & $3.72(0.64)$ & c & $3.56(0.72)$ & $3.64(0.64)$ & $3.38(0.72)$ \\
\hline
\end{tabular}

Patient Safety Grade.

a. Significant difference between "Poor or Failing" and "Acceptable".

b. Significant difference between "Poor or Failing" and "Excellent/Very Good".

c. Significant difference between "Acceptable" and "Excellent/Very Good".

Number of Events Reported.

a. Significant difference between "No events reported" and " 1 to 5 events reported".

b. Significant difference between "No events reported" and " $>5$ events reported".

c. Significant difference between " 1 to 5 events reported" and "> 5 events reported".

decreased frequency of events by $-0.17(\mathrm{p}$-value $=0.002)$ and $-0.15(\mathrm{p}$-value $=0.031)$ respectively $($ See Table 7$)$.

\section{Overall perception of safety}

Perception of patient safety improved by 0.09 (P-Value = 0.008 ) for a one unit increase in the score on supervisor/ manager expectations and actions promoting safety, by 0.20 (P-Value $<0.001$ ) for every unit increase in the score on organizational learning and continuous improvement, and by 0.09 (P-Value $<0.001$ ) for a one unit increase in the score on teamwork within units. A one unit increase in the composites on Staffing, Hospital Management Support for Patient Safety, Hospital Handoffs \& Transitions were also found to increase overall perception of patient safety by 0.13 (p-value < 0.0010, 0.17 ( $\mathrm{p}$-value $<0.001$ ) and 0.08 (p-value $=0.004)$ respectively. A one unit increase in Communication and Openness was associated with -0.06 lower overall perception of patient safety $(p$-value $=0.013$ ) (See Table 7).

Longer years of experience were associated with progressively lower overall perception of patient safety as observed in Table 4. Moreover, respondents who had 1 to 5 years of experience had $-0.11(\mathrm{p}$-value $=0.047)$ lower perception of patient safety. Physical, Occupational, Speech Therapists, Registered Nurses and Unit Assistant/Clerk/Secretary all had lower overall perception of patient safety (Table 7).

\section{Discussion}

This is one of the few large scale studies assessing patient safety culture in one organization in KSA. Findings were able to identify areas of strength (Organizational Learning and Continuous Improvement and Teamwork within units) and weaknesses (Non-punitive response to error, staffing, and Communication Openness). Study findings showed many areas for improvement, particularly in comparison to other countries in the region and around the world. Results on some composites such as nonpunitive response to error, staffing, and communication and openness are lower than countries in the region and the US. However, patient safety culture initiatives are novel in the region since the topic only started garnering attention in the past five years. On the other hand, patient safety has been an area of debate and attention in the US since the publication of the Institute of Medicine (IOM) report in 2001 and as a result, it is natural to find better results on some areas compared to those in KSA and even Lebanon.

Findings at the bi-variate and multi-variate level point to several areas of improvement within the composites that can increase patient safety grade, number of events reported, frequency of events reported and perception of patient safety. It appeared that higher composites on communication and openness, feedback and communication about error and non-punitive response to error 
Table 5 Comparing responses across the two facilities

\begin{tabular}{|c|c|c|c|c|c|}
\hline & \multicolumn{2}{|c|}{ Large } & \multicolumn{2}{|c|}{ Small } & \multirow[b]{2}{*}{ P-Value* } \\
\hline & $\mathbf{N}$ & Mean (SD) & $\mathbf{N}$ & Mean (SD) & \\
\hline Frequency of event reporting & 1054 & $3.84(1.11)$ & 321 & $3.71(1.12)$ & 0.067 \\
\hline Overall perceptions of safety & 1032 & $3.42(0.58)$ & 316 & $3.56(0.63)$ & $<0.001$ \\
\hline Supervisor/manager expectations and actions promoting safety & 1043 & $3.48(0.64)$ & 323 & $3.59(0.62)$ & 0.007 \\
\hline Organizational learning-continuous improvement & 1051 & $3.99(0.59)$ & 325 & $4.06(0.49)$ & 0.275 \\
\hline Teamwork within hospital units & 1066 & $3.91(0.66)$ & 323 & $4.07(0.53)$ & $<0.001$ \\
\hline Communication openness & 1051 & $3.23(0.87)$ & 325 & $3.43(0.79)$ & $<0.001$ \\
\hline Feedback and communication about errors & 1054 & $3.92(0.82)$ & 325 & $3.86(0.90)$ & 0.298 \\
\hline Non-punitive response to error & 1040 & $2.64(0.80)$ & 321 & $2.74(0.77)$ & 0.046 \\
\hline Staffing & 1039 & $2.86(0.63)$ & 322 & $2.84(0.61)$ & 0.691 \\
\hline Hospital management support for patient safety & 1064 & $3.75(0.71)$ & 320 & $3.96(0.67)$ & $<0.001$ \\
\hline Hospital handoffs and transitions & 1030 & $3.43(0.77)$ & 317 & $3.52(0.74)$ & 0.071 \\
\hline \multirow[t]{2}{*}{ Teamwork across hospital units } & 1038 & $3.54(0.69)$ & 320 & $3.73(0.67)$ & $<0.001$ \\
\hline & & N (\%) & & $\mathrm{N}(\%)$ & P-Value \\
\hline \multicolumn{6}{|l|}{ Patient safety grade } \\
\hline Poor or failing & & $38(3.6 \%)$ & & $7(2.1 \%)$ & 0.001 \\
\hline Acceptable & & 277 (26.3\%) & & 57 (17.4\%) & \\
\hline Excellent/Very good & & 740 (70.1\%) & & $263(80.4 \%)$ & \\
\hline \multicolumn{6}{|l|}{ Number of events reported } \\
\hline No event reports & & $505(46.2 \%)$ & & $183(54.5 \%)$ & 0.008 \\
\hline 1 to 5 event reports & & $508(46.5 \%)$ & & $140(41.7 \%)$ & \\
\hline$>5$ events reported & & $80(7.3 \%)$ & & $13(3.9 \%)$ & \\
\hline
\end{tabular}

*Bold and italicized font is to refer to statistically significant p-values.

were associated with lower number of events reported. Moreover, higher scores on staging and teamwork across hospital units were associated with lower frequency of events reported and higher scores on communication and openness were associated with lower perception of patient safety. These finding can be linked to the responses to the question on frequency of event reporting imply a fear of reporting, and this can be linked to some respondents' belief that mistakes were held against them when they report an incident. Fear of reporting can present an impediment to a positive patient safety culture. Reasons for not reporting errors as detailed in literature include fear, humiliation, and the presence of a punitive response to error [15]. There is a need to encourage health professionals, particularly nurses who comprised around half the sampled respondents, to report events given its positive impact in improving patient safety. In fact, evidence in the literature defines three major components to a positive patient safety culture, mainly a just culture, a reporting culture, and a learning culture [2]. A non-punitive environment where hospital employees feel free and confident in reporting events without fear of blame is essential for better event reporting and consequently a safer hospital [5]. Non- punitive response to error was also low in Lebanon where it scored lowest among all dimensions [12].

Staffing also appeared to be a challenge to respondents in this study, as they specifically indicated working longer hours than is best for patient safety, and that they try to do too much too quickly in crisis mode. This finding is critical given the large body of evidence linking the availability of health care providers to population health outcomes [16]. Organizations with an insufficient number of employees have suffered major patient related catastrophes [8]. In cases where the number of employees is lower than optimum to provide patient care, most staff are overworked, burned out, suffer from stress and sleeplessness which may cause lapses in performance which could affect quality and patient outcomes $[8,17]$.

Despite the findings above, many areas of strength were also identified including actions taken by the hospital to improve patient safety, degree of staff support within a unit, working together as a team. Findings in Lebanon linked higher scores on teamwork across hospital units to frequency of events reported. Higher scores on hospital handoffs and transitions were linked to greater likelihood of better perception of safety and also greater likelihood of reporting a higher patient safety grade [12]. 
Table 6 Generalized estimating equations

\begin{tabular}{|c|c|c|c|c|}
\hline & \multicolumn{2}{|c|}{ Patient safety grade } & \multicolumn{2}{|c|}{ Number of events reported } \\
\hline & OR $(95 \% \mathrm{Cl})$ & P-value* & OR $(95 \% \mathrm{Cl})$ & P-value* \\
\hline \multicolumn{5}{|l|}{ Patient safety culture composites } \\
\hline Supervisor/Manager expectations \& actions promoting patient safety & $1.06(1.05-1.08)$ & $<0.001$ & $0.90(0.71-1.16)$ & 0.430 \\
\hline Organizational learning and continuous improvement & $1.91(1.63-2.25)$ & $<0.001$ & $0.89(0.81-0.98)$ & 0.018 \\
\hline Teamwork within units & $1.34(1.14-1.59)$ & 0.001 & $0.88(0.84-0.92)$ & 0.000 \\
\hline Communication openness & $1.25(1.20-1.31)$ & $<0.001$ & $1.05(0.82-1.34)$ & 0.710 \\
\hline Feedback and communications about error & $1.44(1.33-1.56)$ & $<0.001$ & $1.50(1.49-1.51)$ & $<0.001$ \\
\hline Non-punitive response to error & $1.13(1.07-1.20)$ & $<0.001$ & $1.08(1.04-1.13)$ & $<0.001$ \\
\hline Staffing & $1.30(1.28-1.32)$ & $<0.001$ & $0.76(0.70-0.84)$ & $<0.001$ \\
\hline Hospital management support for patient safety & $2.80(2.55-3.08)$ & $<0.001$ & $0.83(0.71-0.97)$ & 0.021 \\
\hline Hospital handoffs \& transitions & $1.09(0.94-1.26)$ & 0.253 & $1.05(0.95-1.16)$ & 0.355 \\
\hline Teamwork across hospital units & $1.13(1.09-1.17)$ & $<0.001$ & $0.94(0.83-1.06)$ & 0.328 \\
\hline \multicolumn{5}{|l|}{ Gender } \\
\hline Male & 1 & & 1 & \\
\hline Female & $0.50(0.39-0.65)$ & $<0.001$ & $0.75(0.62-0.91)$ & 0.003 \\
\hline \multicolumn{5}{|l|}{ Age } \\
\hline Less than 30 years of age & 1 & & 1 & \\
\hline Between 30 and 45 & $0.91(0.89-0.93)$ & $<0.001$ & $1.43(0.96-2.13)$ & 0.076 \\
\hline Between 46 and 55 & $0.74(0.48-1.16)$ & 0.188 & $1.23(0.68-2.22)$ & 0.488 \\
\hline Aged above 55 & $0.66(0.49-0.89)$ & 0.006 & $1.11(0.42-2.98)$ & 0.830 \\
\hline \multicolumn{5}{|l|}{ Experience at the hospital } \\
\hline Less than 1 year & 1 & & 1 & \\
\hline 1 to 5 years & $1.01(0.75-1.36)$ & 0.928 & $0.42(0.37-0.48)$ & 0.928 \\
\hline 6 to 10 years & $1.13(1.09-1.17)$ & $<0.001$ & $0.45(0.37-0.54)$ & $<0.001$ \\
\hline 11 to 15 years & $1.13(1.11-1.15)$ & $<0.001$ & $0.28(0.26-0.31)$ & $<0.001$ \\
\hline 16 to 20 years & $1.31(1.05-1.64)$ & 0.018 & $0.20(0.12-0.32)$ & 0.018 \\
\hline More or equal to 21 years & $0.88(0.56-1.38)$ & 0.578 & $0.27(0.16-0.48)$ & 0.578 \\
\hline \multicolumn{5}{|l|}{ Highest degree } \\
\hline High school level or below & 1 & & 1 & \\
\hline Diploma level & $0.29(0.24-0.35)$ & $<0.001$ & $18.88(14.74-24.19)$ & $<0.001$ \\
\hline Baccalaureate degree & $0.23(0.22-0.25)$ & $<0.001$ & $26.13(24.34-28.05)$ & $<0.001$ \\
\hline Masters degree & $0.13(0.09-0.17)$ & $<0.001$ & $47.61(30.17-75.04)$ & $<0.001$ \\
\hline Doctorate degree & $0.21(0.09-0.50)$ & $<0.001$ & $56.09(7.55-416.96)$ & $<0.001$ \\
\hline Other & $0.24(0.16-0.37)$ & $<0.001$ & $9.57(7.86-11.66)$ & $<0.001$ \\
\hline \multicolumn{5}{|l|}{ Position at the hospital } \\
\hline Administration/Management & 1 & & 1 & \\
\hline Attending/Staff physician & $0.67(0.57-0.79)$ & $<0.001$ & $0.37(0.22-0.62)$ & $<0.001$ \\
\hline Dietician & $0.09(0.02-0.35)$ & 0.001 & $0.74(0.43-1.27)$ & 0.273 \\
\hline Infection control practitioner/Coordinator/Nurse & $0.22(0.08-0.64)$ & 0.006 & $0.91(0.48-1.73)$ & 0.781 \\
\hline Patient care assistant/Hospital Aide/Care partner & $0.85(0.30-2.35)$ & 0.748 & & \\
\hline Pharmacist & $0.37(0.06-2.16)$ & 0.270 & $1.32(1.06-1.65)$ & 0.015 \\
\hline Physical, occupational, speech therapist & $0.32(0.08-1.19)$ & 0.088 & $0.15(0.12-0.18)$ & $<0.001$ \\
\hline Physician assistant/Nurse practitioner & & & $0.68(0.68-0.69)$ & $<0.001$ \\
\hline
\end{tabular}


Table 6 Generalized estimating equations (Continued)

\begin{tabular}{|c|c|c|c|c|}
\hline Registered nurse & $0.35(0.13-0.93)$ & 0.034 & $0.86(0.79-0.94)$ & 0.001 \\
\hline Resident physician/Physician in training & $0.29(0.12-0.75)$ & 0.010 & $1.14(0.48-2.71)$ & 0.770 \\
\hline Respiratory therapist & $0.13(0.06-0.27)$ & $<0.001$ & $1.58(1.3-1.91)$ & $<0.001$ \\
\hline Quality staff & $0.15(0.03-0.65)$ & 0.011 & $1.23(0.49-3.06)$ & 0.656 \\
\hline Unit assistant/Clerk/Secretary & $0.32(0.20-0.51)$ & $<0.001$ & $0.17(0.13-0.21)$ & $<0.001$ \\
\hline Technician (e.g., EKG, Lab, Radiology) & $0.95(0.62-1.45)$ & 0.803 & $0.32(0.14-0.75)$ & 0.009 \\
\hline Other & $0.48(0.11-2.06)$ & 0.324 & $0.26(0.11-0.59)$ & 0.001 \\
\hline \multicolumn{5}{|l|}{ Interaction with patients } \\
\hline No & $1.08(0.79-1.46)$ & 0.633 & $1.18(0.97-1.43)$ & 0.102 \\
\hline Yes & 1 & & 1 & \\
\hline \multicolumn{5}{|l|}{ Hospital size } \\
\hline Small & $1.58(1.25-1.99)$ & $<0.001$ & $0.62(0.60-0.65)$ & $<0.001$ \\
\hline Large & 1 & & 1 & \\
\hline $\mathrm{N}$ & 1005 & & 1029 & \\
\hline
\end{tabular}

*Bold and italicized font is to refer to statistically significant $p$-values.

One interesting observation is that related to the impact of small hospital size on patient safety culture outcomes. The study noted a significant association between small facility size and higher patient safety grade and number of events reported. Small hospital size has been found to be associated with higher overall average percent positive response on the patient safety culture composites and a higher percentage of respondents giving their work areas a patient safety grade of "Excellent" or "Very Good" [18]. On a related note, a study in Lebanon found a link between hospital size and better quality results in a study on impact of accreditation on quality of care [19]. Size is particularly important to consider given that evidence from the literature documenting its effect on managerial practices in healthcare organizations. For instance, large organizations find it easier to comply with accreditation requirements (such as assessment of patient safety culture) and derive greater value and benefit compared to smaller organizations given the lower financial burden in comparison to their overall budgets [20]. However, the edge that smaller organizations possess is their homogenous culture and shared values [21]. Larger organizations are more hierarchical and bureaucratic making implementation of quality initiatives challenging [22]; this also affects employees' attachment to these organizations and consequently their performance [21]. Evidence from international literature link small hospital size ( $<100$ beds) to increased formal organizational leadership in relation to patient safety events which in effect lead to better patient safety behaviors at the organizational level. This is due to the fact that in small hospitals (where the economic burden of safety programs may be large), formal leadership is closer to the front lines and has greater impact than in larger hospitals [23].
Some strengths and limitations to this study should be acknowledged. One of the strengths of this study is its use of the HSOPSC which is the most commonly used tool to assess the culture of safety in hospitals. This study also utilized the Arabic version of the survey which was translated and validated in in another Arab country [12,13]. Despite the fact that most employees in the sampled organizations are expatriates and should thus be fluent in English, Arabic remains the native language that most employees feel more comfortable with. As such, providing employees with an Arabic version of the survey may have allowed them to better understand and respond to the specific items of the survey. It should be acknowledged that while this study targeted a major health care organization in Riyadh and was able to obtain a large sample size representing the majority of staff, results should be interpreted with caution and not be generalized. However, it does offer insight into the current status of patient safety culture and was able to build on and validate the findings of previous research, particularly after major work has been conducted on accreditation in healthcare organizations in KSA including the facilities in this specific study.

Some may consider the low Cronbach's alpha values a limitation (values ranged between 0.214 and 0.892). The HSOPSC user's guide indicates that a value equal to or greater than 0.6 is acceptable [7] whereas Bowling [24] sets 0.5 or above as an acceptable value. Still, evidence shows that lower values of Cronbach's alpha are expected when using psychological constructs due to the diversity of the items that are being measured [25]. A study in Turkey also reported values as low as 0.4 [11]. In Lebanon, Cronbach's alpha values were as low as 0.451 and were attributed to the wide range of respondents [12]. 
Table 7 Linear regression model

\begin{tabular}{|c|c|c|c|c|}
\hline & \multicolumn{2}{|c|}{ Frequency of events reported } & \multicolumn{2}{|c|}{ Perception of patient safety } \\
\hline & Beta (Standard error) & P-value* & Beta (Standard error) & P-value* \\
\hline \multicolumn{5}{|l|}{ Patient safety culture composites } \\
\hline Supervisor/Manager expectations \& actions promoting patient safety & $-0.08(0.06)$ & 0.178 & $0.09(0.03)$ & 0.008 \\
\hline Organizational learning and continuous improvement & $0.24(0.08)$ & 0.002 & $0.20(0.04)$ & $<0.001$ \\
\hline Teamwork within units & $0.04(0.07)$ & 0.506 & $0.09(0.03)$ & 0.007 \\
\hline Communication openness & $-0.04(0.05)$ & 0.440 & $-0.06(0.03)$ & 0.013 \\
\hline Feedback and communications about error & $0.43(0.06)$ & $<0.001$ & $0.002(0.03)$ & 0.955 \\
\hline Non-punitive response to error & $-0.02(0.05)$ & 0.715 & $0.006(0.02)$ & 0.817 \\
\hline Staffing & $-0.17(0.05)$ & 0.002 & $0.13(0.03)$ & $<0.001$ \\
\hline Hospital management support for patient safety & $0.11(0.06)$ & 0.066 & $0.17(0.03)$ & $<0.001$ \\
\hline Hospital handoffs \& transitions & $0.06(0.05)$ & 0.237 & $0.08(0.03)$ & 0.004 \\
\hline Teamwork across hospital units & $-0.15(0.07)$ & 0.031 & $0.006(0.04)$ & 0.868 \\
\hline \multicolumn{5}{|l|}{ Gender } \\
\hline Male & $0.05(0.10)$ & 0.650 & $0.02(0.05)$ & 0.686 \\
\hline Female & 0 & & 0 & \\
\hline \multicolumn{5}{|l|}{ Age } \\
\hline Less than 30 years of age & 0 & & 0 & \\
\hline Between 30 and 45 & $-0.09(0.09)$ & 0.337 & $-0.10(0.05)$ & 0.036 \\
\hline Between 46 and 55 & $0.08(0.15)$ & 0.572 & $-0.15(0.08)$ & 0.046 \\
\hline Aged above 55 & $0.20(0.20)$ & 0.317 & $-0.21(0.10)$ & 0.046 \\
\hline \multicolumn{5}{|l|}{ Experience at the hospital } \\
\hline Less than 1 year & 0 & & 0 & \\
\hline 1 to 5 years & $0.03(0.10)$ & 0.791 & $-0.11(0.05)$ & 0.047 \\
\hline 6 to 10 years & $-0.02(0.13)$ & 0.867 & $-0.06(0.07)$ & 0.373 \\
\hline 11 to 15 years & $-0.01(0.16)$ & 0.927 & $-0.04(0.08)$ & 0.633 \\
\hline 16 to 20 years & $0.12(0.18)$ & 0.510 & $-0.004(0.09)$ & 0.962 \\
\hline More or equal to 21 years & $-0.07(0.20)$ & 0.741 & $-0.04(0.10)$ & 0.649 \\
\hline \multicolumn{5}{|l|}{ Highest degree } \\
\hline High school level or below & 0 & & 0 & \\
\hline Diploma level & $-0.19(0.31)$ & 0.528 & $0.06(0.15)$ & 0.691 \\
\hline Baccalaureate degree & $-0.23(0.31)$ & 0.446 & $0.08(0.15)$ & 0.587 \\
\hline Masters degree & $-0.01(0.34)$ & 0.966 & $-0.10(0.17)$ & 0.561 \\
\hline Doctorate degree & $0.12(0.40)$ & 0.758 & $-0.07(0.20)$ & 0.711 \\
\hline Other & $-0.54(0.36)$ & 0.134 & $0.05(0.18)$ & 0.769 \\
\hline \multicolumn{5}{|l|}{ Position at the hospital } \\
\hline Administration/Management & $0.12(0.23)$ & 0.599 & $-0.05(0.12)$ & 0.701 \\
\hline Attending/Staff physician & $-0.26(0.28)$ & 0.337 & $0.05(0.14)$ & 0.736 \\
\hline Dietician & $-0.22(0.38)$ & 0.565 & $-0.33(0.20)$ & 0.102 \\
\hline Infection control practitioner/Coordinator/Nurse & $0.21(0.33)$ & 0.53 & $-0.05(0.17)$ & 0.791 \\
\hline Patient care assistant/Hospital aide/Care partner & $0.58(0.29)$ & 0.045 & $-0.11(0.15)$ & 0.479 \\
\hline Pharmacist & $0.19(0.29)$ & 0.511 & $0.11(0.16)$ & 0.477 \\
\hline Physical, occupational, speech therapist & $-0.22(0.26)$ & 0.393 & $-0.29(0.13)$ & 0.029 \\
\hline Physician assistant/Nurse practitioner & $-0.05(0.48)$ & 0.925 & $-0.31(0.25)$ & 0.219 \\
\hline
\end{tabular}


Table 7 Linear regression model (Continued)

\begin{tabular}{|c|c|c|c|c|}
\hline Registered nurse & $0.29(0.15)$ & 0.06 & $-0.32(0.07)$ & $<0.001$ \\
\hline Resident physician/Physician in training & $-0.71(0.30)$ & 0.019 & $-0.13(0.16)$ & 0.408 \\
\hline Respiratory therapist & $-0.19(0.62)$ & 0.759 & $-0.59(0.33)$ & 0.072 \\
\hline Quality staff & $-0.18(0.39)$ & 0.638 & $-0.19(0.19)$ & 0.324 \\
\hline Unit assistant/Clerk/Secretary & $0.24(0.23)$ & 0.298 & $-0.29(0.12)$ & 0.019 \\
\hline Technician (e.g., EKG, Lab, Radiology) & $0.01(0.17)$ & 0.934 & $-0.15(0.09)$ & 0.104 \\
\hline Other & 0 & & 0 & \\
\hline \multicolumn{5}{|l|}{ Interaction with patients } \\
\hline No & 0 & & 0 & \\
\hline Yes & $0.06(0.11)$ & 0.567 & $0.004(0.06)$ & 0.939 \\
\hline \multicolumn{5}{|l|}{ Hospital size } \\
\hline Small & 0 & & 0 & \\
\hline Large & $0.09(0.08)$ & 0.268 & $-0.05(0.04)$ & 0.273 \\
\hline $\mathrm{N}$ & 1008 & & 1001 & \\
\hline
\end{tabular}

*Bold and italicized font is to refer to statistically significant $p$-values.

Exploring the Cronbach's alpha across respondent's positions in this study also showed variation which may indicate that respondents in specific positions may be more (or less) aware about specific areas of patient safety culture challenges. This finding may require additional analysis to understand how different positions within the hospital may affect performance and consequently quality of care.

There are limited opportunities for countries to compare their performance against countries in the same region or around the world. This is the first study to compare such results in the region and the results presented in the comparative analysis component detail areas where the findings in KSA are similar and different than Lebanon, and USA. The comparative analysis required obtaining detailed data from each country pertaining to percent positive responses and sample size. Detailed results were available for sample size for each of the composites for both Lebanon and KSA but not for USA. In the latter cases, the total number of cases was used instead which was 567,703 for USA. This may have affected the results of the comparative analysis. Despite these limitations, the significant differences with Lebanon and USA provide a number of insights for the hospital in Riyadh on areas of strength and areas requiring some additional improvement.

\section{Conclusion}

Investing in practices that strengthen patient safety is crucial if hospitals are to improve overall performance and quality of services. There is significant work to be done in the sampled organizations and in the context of the region in general to improve patient safety practices and culture. Patient safety should be integrated into educational programs for health professionals and embedded within the foundation of organizational structures. Health professionals needed not only continuing education but organizational support in the form of policies, governance and reporting structures. There is a need to give priority to patient safety culture assessments in health organizations and more importantly to make changes based on the results of such assessments. Regular assessment and reporting of patient safety culture is also required by some national and international accreditation programs. Such assessments can indicate areas requiring improvement and as such help devise targeted efforts that focus on investing in and improving patient safety and overall performance. It should be noted that assessing the patient safety culture is only the first step in a long process for identifying areas for improvement that hospitals can address to avert critical patient outcomes. Longitudinal research based on regular assessment of patient safety culture is needed to determine whether tangible improvements resulted from implemented quality improvement plans and affected the culture of safety or had an impact on clinical outcomes.

\section{Ethical considerations}

The protocol for the original study was approved by the American University of Beirut Internal Review Board (protocol number FHS.FE.03). No additional local ethical review was required as advised by hospital administration. The study adhered to all ethical considerations pertaining to confidentiality of the responses provided by employees and informed consent form was provided and anonymity of responses was ensured. The facility provided an anonymous drop box to return the questionnaire at clearly designated points. The survey was also available in an online format and adhered to all ethical standards. 


\section{Abbreviations}

HSOPSC: Hospital survey on patient safety culture; IOM: Institute of medicine; KSA: Kingdom of Saudi Arabia; OR: Odds ratio; POC: Points of contact.

\section{Competing interests}

The authors declare that they have no competing interests.

\section{Authors' contributions}

FE contributed to the conception, study design, tool development, data collection, as well as data analysis and interpretation of results in addition to development of the manuscript. FS and NAG contributed to data collection and coordination in addition to manuscript review. DJ also contributed to data analysis and manuscript write-up and review. AA contributed to manuscript write-up and review of the final manuscript. All authors read and approved the final manuscript.

\section{Acknowledgements}

Authors would like to thank Mr. Alaa Abu Al Rub, Ms. Alicia Reyes, Ms. Mariam Napuli, Ms. Aisha Charmaine May, and Ms. Mary Johns for their support.

\section{Author details}

'Department of Health Management and Policy, Faculty of Health Sciences, American University of Beirut, Beirut, Lebanon. ${ }^{2}$ Department of Clinical Epidemiology and Biostatistics, McMaster University, Canada, MML-417, 1280 Main St. West, Hamilton, Ontario L8S 4L6, Canada. ${ }^{3}$ King Saud University, Riyadh, Kingdom of Saudi Arabia.

\section{Received: 30 January 2013 Accepted: 21 February 2014}

Published: 12 March 2014

\section{References}

1. Nieva V, Sorra J: Safety culture assessment: a tool for improving patient safety in health care organizations. Qual Saf Health Care 2009, 12:ii17-ii23. Available from: http://qshc.bmj.com/content/12/suppl_2/ii17.full.pdf [Accessed 20th October 2009] [Online] 2003.

2. World Alliance for Patient Safety: Summary of the evidence on patient safety: implications for research. Geneva, Switzerland: World Health Organization; 2008.

3. Hellings J, Schrooten W, Klazinga N, Vleugels A: Challenging patient safety culture: survey results. Int J Health Care Qual Assur 2007, 20:620-632.

4. Deilkas E, Hofoss D: Psychometric properties of the Norwegian version of the Safety Attitudes Questionnaire $(\mathrm{SAQ})$, generic version (short form 2006). BMC Health Serv Res 2009, 8. Available at: http://www.biomedcentral. com/1472-6963/8/191 [Accessed 9th October 2009] [Online] 2008.

5. Smits M, Wagner C, Spreeuwenberg P, Wal G, Groenewegen PP: Measuring patient safety culture: an assessment of the clustering of responses at unit level and hospital level. Qual Saf Health Care 2009, 18:292-296.

6. Blegen M, Gearhart S, O'Brien R, Sehgal N, Alldredge B: AHRQ's Hospital survey on patient safety culture: psychometric analyses. J Patient Saf 2009, 5:139-144.

7. Sorra JS, Nieva VF: Hospital Survey On Patient Safety Culture. Rockville, MD: Agency for Healthcare Research and Quality. AHRQ; 2004. Publication No. 04-0041.

8. Sanders J, Cook G: ABC of Patient Safety. Oxford: United Kingdom, Blackwell; 2007.

9. Al-Ahmadi TA: Measuring patient safety culture in Riyadh's hospitals: a comparison between public and private hospitals. J Egypt Public Health Assoc 2009, 84(5-6):479-500.

10. Alahmadi HA: Assessment of patient safety culture in Saudi Arabian hospitals. Qual Saf Health Care 2010, 19(5):e17.

11. Bodur S, Filiz E: A survey on patient safety culture in primary healthcare services in Turkey. Int $J$ Qual Health Care 2009, 21:348-355.

12. El-Jardali F, Jaafar M, Dimassi H, Jamal D, Hamdan R: The current state of patient safety culture in Lebanese hospitals: a study at baseline. Int J Qual Health Care 2010, 22(5):386-95.

13. El-Jardali F, Dimassi H, Jamal D, Jaafar M, Hemadeh N: Predictors and outcomes of patient safety culture in hospitals. BMC Health Serv Res 2011, 11:45.

14. Sorra J, Famolaro T, Dyer N, Nelson D, Khanna K: Rockville, MD: Hospital Survey on Patient Safety Culture: 2009 Comparative Database Report, AHRO Publication No. 09-0030. Rockville, MD: Agency for Healthcare Research and
Quality; 2009. Available on: http://psnet.ahrq.gov/resource.aspx? resourcelD=10206

15. VanGeest JB, Cummins DS: An Educational Needs Assessment For Improving Patient Safety: Results Of A National Study Of Physicians And Nurses. National Patient Safety Foundation; 2003. White Paper Report 3.

16. El-Jardali F, Jamal D, Abdallah A, Kassak K: Human resources for health planning and management in the Eastern Mediterranean region: facts, gaps and forward thinking for research and policy. Human Resources for Health Journal 2007, 5:9.

17. Baldwin DC Jr, Daugherty SR, Tsai R, Scotti MJ Jr: A national survey of residents' self-reported work hours: thinking beyond specialty. Acad Med 2003, 78:1154-63.

18. Sorra J, Famolaro T, Dyer N, Khanna K, Nelson D: Hospital Survey on Patient Safety Culture 2011 user comparative database report. (Prepared by Westat, Rockville, MD, under Contract No. HHSA 290200710024C). Rockville, MD: Agency for Healthcare Research and Quality; 2011. AHRQ Publication No. 11-0030.

19. El-Jardali F, Jamal D, Dimassi H, Ammar W, Tchaghchaghian V: The Impact of Hospital Accreditation on Quality of Care: Perception of Lebanese Nurses. Int J Qual Health Care 2008, 20(5):363-371.

20. Montagu D, Department for International Development Health Systems Resource Centre: Accreditation And Other External Quality Assessment Systems For Healthcare: Review Of Experience And Lessons Learned. London; 2003. Available on: http://www.heart-resources.org/wp-content/uploads/2012/10/ Accreditation-and-other-external-quality-assessments.pdf.

21. El-Jardali F: The impact of hospital rationalization and the interrelationships among organizational culture and nursing care processes on health related patient outcomes. In Thesis (Ph.D.). Carleton University, Canada; 2003.

22. Ammar W, Wakim R, Hajj I: Accreditation of hospitals in Lebanon: a challenging experience. East Mediterr Health J 2007, 13:138-149.

23. Ginsburg LR, Chuang YT, Berta WB, Norton PG, Ng P, Tregunno D, Richardson J: The relationship between organizational leadership for safety and learning from patient safety events. Health Serv Res 2010, 45(3):607-632.

24. Bowling A: Research Methods in Health. Buckingham: Open University Press; 1997.

25. Field A: Discovering Statistics Using Spss (And Sex And Drugs And Rock 'N' Roll). 3rd edition. London: SAGE Publications; 2009.

\section{doi:10.1186/1472-6963-14-122}

Cite this article as: El-Jardali et al:: Patient safety culture in a large teaching hospital in Riyadh: baseline assessment, comparative analysis and opportunities for improvement. BMC Health Services Research 2014 14:122.

\section{Submit your next manuscript to BioMed Central and take full advantage of:}

- Convenient online submission

- Thorough peer review

- No space constraints or color figure charges

- Immediate publication on acceptance

- Inclusion in PubMed, CAS, Scopus and Google Scholar

- Research which is freely available for redistribution 